\title{
PENGEMBANGAN USAHA KECIL DAN MENENGAH PRODUSEN MAKANAN BERBAHAN BAKU LOKAL
}

\section{THE DEVELOPMENT OF SMALL AND MEDIUM ENTERPRISES PRODUCING FOODS MADE LOCAL RAW MATERIAL}

\author{
${ }^{1)}$ Jaka Sriyana, ${ }^{2}$ Chynthia Pradiftha Sari \\ ${ }^{1}$ Program Studi Ilmu Ekonomi, Universitas Islam Indonesia, Indonesia. \\ ${ }^{2}$ Program Studi Farmasi, Universitas Islam Indonesia, Indonesia. \\ Jl. Kaliurang km. 15,5 Sleman, Yogyakarta 55584. \\ e-mail: jakasriyana@uii.ac.id
}

\begin{abstract}
ABSTRAK
Tujuan program pengabdian masyarakat di Desa Wringinputih ini adalah menemukan strategi pengembangan usaha kecil dan menengah (UKM) makanan olahan berbahan baku lokal. Kelompok usaha yang menjadi obyek pengabdian adalah kelompok UKM bidang makanan berbahan dasar dari ketela. Untuk menemukan berbagai strategi yang dipilih, digunakan analisis Strength, Weaknesses, Opportunity and Threat (SWOT). Strategi yang direkomendasikan untuk pengembangan usaha adalah peningkatan kualitas produksi, pengurusan perijinan industri rumah tangga (P-IRT), peningkatan kualitas pengemasan produk, dan pemasaran. Hasil kegiatan pengabdian menghasilkan produk berupa (1) peningkatan kualitas produk makanan berbahan baku ketela dengan penggunaan mesin peniris minyak (spinner), (2) hasil diversifikasi jenis makanan olahan berbahan baku ketela dan pepaya, (3) hasil pelatihan dan pengurusan P-IRT, (4) desain kemasan produk makanan berbahan baku ketela dan pepaya, dan (5) rancangan pemasaran produk makanan olahan.
\end{abstract}

Kata Kunci : Singkong, Usaha Kecil Dan Menengah, Sertifikat P-IRT

\section{ABSTRACT}

The purpose of community service program in Wringinputih Village is to find the strategy of developing small and medium enterprises (SMEs) of processed foods made from local raw materials. Group of business as object of dedication is group of food industry based SMEs from cassava. To find the various strategies of SME's development, we used Strength, Weaknesses, Opportunity and Threat (SWOT) analysis. The recommended strategies for business development are improving the quality of production, managing the home industry licensing (Perijinan Industri Rumah Tangga/P-IRT), improving the quality of product packaging, and new marketing design. The result of the community services are (1) the improvement of the quality of food product made from raw sweet potatoes with the use of the oil spinner machine, (2) the diversification of the processed foods made from raw cassava and papaya, (3) the result of training and management of P-IRT, (4) packaging design of food products made from cassava and papaya, (5) marketing design of processed food products.

Keywords: Cassava, Small And Medium Entrepreneurs, Certificate P-IRT

Submited : 10 Nopember $2017 \quad$ Revision : 17 Desember $2017 \quad$ Accepted : 5 Maret 2018

\section{PENDAHULUAN}

Desa Wringinputih secara geografis berada di Kecamatan Borobudur Kabupaten Magelang Jawa Tengah, yang memiliki potensi sumber daya alam pertanian dan perkebunan yang sangat besar khususnya tanaman singkong. Hasil panen singkong di Desa Wringinputih belum dimanfaatkan dengan baik oleh 
masyarakat setempat, yang hanya dipasarkan secara langsung oleh warga sebagai sarana untuk mendapatkan penghasilan. Sebagian warga yang menyadari besarnya potensi tersebut berinisiatif untuk melakukan usaha pengolahan ketela menjadi produk olahan pangan berbasis ketela, antara lain; criping, kemplang, kripik dan lain sebagainya

Masyarakat Wringinputih yang memiliki usaha olahan pangan berbasis ketela belum memiliki kesadaran dalam rangka meningkatkan nilai jual hasil produksi olahan ketela. Seiring berjalannya waktu, pengusaha produksi ketela mulai sadar bahwa nilai jual hasil produksi mereka harus ditingkatkan, agar pemasaran produk mereka menjadi berkembang. Produk utama mereka, yaitu ketela, umbinya dikenal luas sebagai makanan pokok penghasil karbohidrat dan daunnya sebagai sayuran. Banyaknya manfaat dan kegunaan ketela dalam kehidupan masyarakat wringinputih, menjadikan masyarakat termotivasi untuk mengoptimalkan hasil panen ketela dan pepaya menjadi produk lain untuk meningkatkan tingkat kesejahteraan dan kemakmuran ekonomi masyarakat sekitar. Keberhasilan program pengembangan UKM untuk meningkatkan pendapatan masyarakat dipengaruhi oleh kondisi dan kearifan lokal (Pattinama, 2009; Sahudiyono, 2009; Yulianto, 2005).

\section{Beberapa kendala penjualan} produk makanan olahan adalah belum adanya sertifikat perijinan industri rumah tangga (P-IRT) untuk masyarakat yang memiliki usaha pengolahan ketela. Kebanyakan masyarakat menganggap bahwa pengurusan P-IRT itu berat dan susah untuk dilakukan. Pada kenyataannya, banyak masyarakat yang tertarik untuk mengurus P-IRT tersebut sebagai salah satu syarat untuk pengembangan pemasaran. Masyarakat memerlukan penjelasan mengenai prosedur dan tahaptahap pendaftarannya, sehingga dapat membuka jalan pengurusan P-IRT bagi pengusaha industri rumah tangga.

Menurut Dinas Kesehatan, Perusahaan Industri Rumah Tangga (PIRT) adalah perusahaan pangan yang memiliki tempat usaha di tempat tinggal dengan peralatan pengolahan pangan manual hingga semi otomatis. Di dalam produksi industri rumah tangga seringkali di temukan hal - hal yang tidak sesuai, bahkan keluar dari kaidah kesehatan atau prosedur higenis dan sanitasi yang telah digariskan. Hal ini disebabkan karena kurangnya pengetahuan dari pelaku P-IRT itu sendiri, modal yang dimiliki, dan pemahaman tentang hygiene sanitasi yang masih kurang. Kebanyakan dari pengolah ketela banyak tidak lolos uji laboratorium karena masih banyak jumlah minyak yang terdapat di dalam produk olahan ketela.

Dengan adanya sertifikat industri rumah tangga (P-IRT), usaha rumah tangga milik masyarakat sekitar Desa Wringinputih bisa meningkatkan kepercayaan konsumen mereka kepada produk olahan mereka. Walaupun Pemerintah Desa telah memfasilitasi Penyuluhan sertifikat industri rumah tangga (PIRT), ternyata banyak pengusaha ketela yang tidak lolos pengujian laboratorium di Dinas Kesehatan.

Untuk membantu memperlancar pengurusan P-IRT kepada masyarakat di Desa Wringinputih perlu adanya mesin Spinner yang berfungsi untuk meniriskan olahan ketela dari minyak yang masih menempel pada produk tersebut. Selain itu, mesin tersebut dapat meningkatkan kualitas produk makanan olahan. Kondisi ini membuktikan perlunya pelaku UKM mengembangkan teknologi untuk peningkatan kualitas produksi (Rachman, et al, 2016; Sutrisno, 2011). Dari pengalaman sebelumnya, banyak 
pengusaha di bidang makanan yang gagal mendapatkan surat P-IRT karena tidak lulus tes laboraturium, karena banyaknya minyak yang menempel di makanan tersebut. Gambaran tentang skala sumber bahan baku ketela sebagai bahan dasar makanan olahan dipaparkan pada Tabel 1.

Tabel 1. Distribusi Hasil Bumi Ketela di 4 Dusun Di Desa Wringinputih

\begin{tabular}{llll}
\hline \multirow{2}{*}{ Nama Dusun } & \multicolumn{2}{c}{ Hasil Bumi } \\
\cline { 3 - 4 } No. & & Ketela & Lain-Lain \\
\hline 1 & Bojong & 337.3355 Ton & 69.3412 Ton \\
\hline 2 & Karangmalang & 270.6709 Ton & 55.6379 Ton \\
\hline 3 & Srigentan & 253.0788 Ton & 52.0217 Ton \\
\hline 4 & Sriyasan & 167.6904 Ton & 34.4697 Ton \\
\hline
\end{tabular}

Sumber : Desa Wringinputih dalam Angka, 2015

Adapun berbagai potensi atau kekuatan dan kelemahan kelompok usaha makanan olahan ketela di wilayah tersebut ditampikan pada Tabel 2.

Tabel 2. Kekuatan dan Kelemahan Masyarakat Sasaran Kelompok Usaha

\begin{tabular}{|c|c|}
\hline Potensi/Kekuatan & Kelemahan \\
\hline $\begin{array}{l}\text { 1. Jumlah anggota } 20 \text { orang } \\
\text { 2. Sudah memiliki tempat usaha } \\
\text { sendiri. } \\
\text { 3. Adanya dukungan dari pemerintah } \\
\text { desa. } \\
\text { 4. Kemauan yang keras dari } 3 \text { para } \\
\text { anggota kelompok wanita tani. } \\
\text { 5. Daya dukung bahan baku ketela } \\
\text { melimpah. }\end{array}$ & $\begin{array}{ll}\text { 1. } & \text { Belum memiliki mesin produksi } \\
\text { 2. } & \text { Penggiling ketela dan peralatan } \\
& \text { olahan makanan lainya. } \\
\text { 3. } & \text { Jenis olahan makanan bahan dasar } \\
\text { ketela masih terbatas. } \\
\text { 4. }\end{array}$ \\
\hline
\end{tabular}

Pada umumnya UKM menghadapi berbagai keterbatasan sumber daya manusia, produksi, modal dan manajemen (Hamdani \& Awatara, 2011; Sijabat, 2015). Dari pengamatan lapangan dan wawancara dengan pengusaha makanan, beberapa permasalahan yang dihadapi oleh anggota kelompok UKM wilayah tersebut adalah:
1) Hanya terdapat 4 (empat) jenis olahan makanan dengan bahan

dasar ketela dari turunan 1 (satu/pertama).

2) Masih kurangnya pengetahuan tentang kandungan gizi dan berbagai jenis makanan yang dihasilkan dari ketela. 
3) Jumlah anggota kelompok wanita tani didominasi oleh generasi tua. (usia di atas 40 tahun sejumlah 14 orang (70\%) dari 20 anggota.

4) Masih dibutuhkannya alatalat/fasilitas pendukung peningkatan kuantitas dan kualitas olahan makanan dari ketela seperti mesin giling ketela menjadi tepung, mesin oven makanan, dan meja produksi.

5) Belum adanya proses labelling dan packaging dan penjualan yang baik.

6) Masih kurangnya upaya memperkenalkan dan menjual produknya ke masyarakat luas, baik terkait kesiapan sumber daya manusianya maupun sarana pemasarannya.

Atas dasar berbagai masalah tersebut, makakegiatan pengabdian masyarakat dalam bentuk pengabdian masyarakat KKN-PPM ini memiliki tujuan untuk pengembagan usaha UKM produsen makanan berbahan baku lokal yang meliputi (1) peningkatan kualitas produk makanan (2) diversifikasi jenis makanan olahan, (3) pelatihan dan pengurusan PIRT, (4) desain kemasan produk makanan, dan (5) rancangan pemasaran produk makanan olahan.

Dalam pelaksanaan program pengabdian masyarakat dalam skim KKNPPM ini yang menjadi lembaga mitra adalah Pemerintah Desa Wringinputih. Pemerintah Desa Wringinputih sebagai pemerintahan terkecil yang mempunyai tugas dan wewenang untuk memberdayakan masyarakat sudah menjalin kerjasama dengan Universitas Islam Indonesia melalui permohonan secara resmi untuk pendampingan pemberdayaan masyarakat. Salah satu program yang akan dikerjakan bersama adalah pemberdayaan kelompok UKM ini.
Pemerintah Desa Wringinputih berperan sebagai fasilitator dalam pelatihanpelatihan untuk mengembangkan potensi dan aktifitas pengolahan makanan bahan dasar ketela dari kelompok UKM. Selain itu Pemerintah Desa Wringinputih juga memberikan fasilitas berupa rumah produksi untuk peningkatan produksi olahan makanan bahan dasar ketela

\section{METODE}

Berdasarkan permasalahan tesebut dapat dilakukan analisis SWOT untuk menemukan strategi penyelesaian masalah. Analisis mengunakan analisis SWOT adalah identifikasi berbagai faktor secara sistematis untuk merumuskan strategi yang harus dilakukan untuk menyelesaikan masalah Situmorang, (2007). Analisis ini didasarkan pada logika yang dapat memaksimalkan kekuatan (strength) dan peluang (opportunities), namun secara bersama-sama dapat meminimalkan kelemahan (weakness) dan ancaman (threats). Dengan demikian kebijakan strategis harus menganalisis faktor-faktor strategis organisasi yang terdiri atasa kekuatan, kelemahan, peluang dan ancaman pada kondisi yang ada saat ini (Suharto, 2010; Wardhani, 2010).

Hasil dari analisis SWOT tersebut kemudian dapat dibuat urutan prioritas program berdasarkan masing-masing aspek, yaitu aspek sumber daya manusia, sarana-prasarana, kelembagaan dan pemasaran. Dalam mengatasi permasalahan tersebut diatas maka metode yang digunakan supaya program dapat berkelanjutan adalah dengan kaderisasi, pelatihan, pendampingan, studi lapangan, dan implementasi 


\section{HASIL DAN PEMBAHASAN}

Dengan mengaplikasikan metode analisis SWOT maka dapat dirumuskan berbagai prioritas strategi pemecahan masalah berdasarkan hasil analisis SWOT berikut :

1. Pendampingan penyusunan potensi pengembangan produk olahan makanan berbahan baku lokal.

2. Penyuluhan dan pelatihan serta (Focus Group Discussion) pengurusan Perijinan Industri Rumah Tagga (PIRT).

3. Pelatihan program pengembangan pemasaran produk hasil olahan makanan.

4. Pendampingan pembuatan sarana dan prasarana media pemasaran.

5. Penyuluhan tentang pengembangan potensi desa dalam menjaga ketahanan pangan berdasar sumber daya lokal.

Pelaksanaan kegiatan pengabdian masyarakat pada kelompok UKM Desa Wringinputih menghasilkan beberapa kegiatan dan produk, yaitu:

1) Program penyuluhan kepada anggota kelompok UKM tentang nilai gizi, variasi jenis dan turunan olahan makanan dari ketela beserta usaha diversifikasi produk. Dari kegiatan ini memberikan hasil berupa peningkatan pemahaman anggota UKM tentang perlunya diversifikasi produk serta hasil produk diversifikasi berupa Brownies dari ketela seperti gambar berikut (Gambar 1):

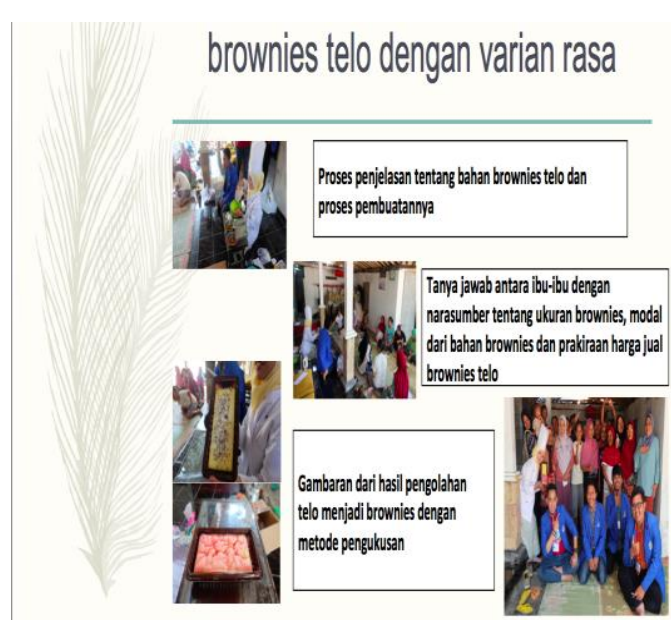

Gambar 1. Proses Pelatihan Diversifikais Produk Makanan

Pelatihan packaging produk hasil olahan makanan dari ketela dan strategi pemasarannya. Kegiatan ini memberikan hasil berupa contoh-contoh packedging produk ceriping ketela seperti gambar berikut ini :

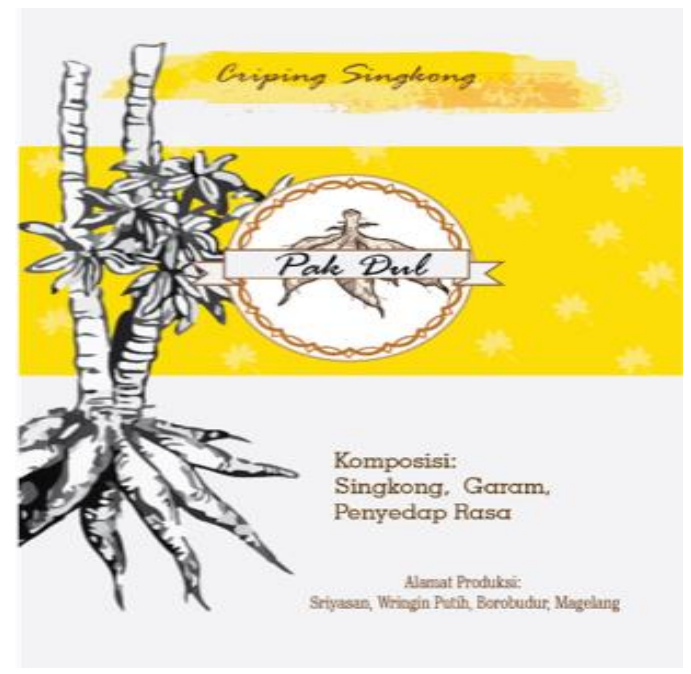

Gambar 2. Contoh packedging produk

2) Program penyuluhan ke anggota kelompok, utamanya generasi muda terkait dengan keunggulan ketela dan pentingnya pelesatariannya sebagai salah satu ketahanan pangan lokal. Hasil pelatihan ini berupa tersusunnya master plan 
pengembangan potensi wisata desa berbasis makanan olahan berbahan baku lokal.

3) Peningkatan fasilitas produksi untuk mendukung peningkatan kuantitas dan kualitas hasil olahan makanan dari bahan dasar ketela, berupa mesin giling ketela menjadi tepung, mesin oven makanan, mesin pemanaas press plastik, meja produksi. Hasil pelatihan ini berupa proses dan dokumen kelengkapan untuk pengajuan P-IRT.

4) Pelatihan pemasaran produk yang efektif, meliputi : (1) pelatihan sumber daya pemasaran yang berorientasi konsumen, (2) pembuatan leaflet, (3) pembuatan catalog produk, (4) membuat website kelompok dan produknya. Hasil pelatihan ini berupa berbagai leaflet untuk sarana pemasaran produk ketela dan grownies (Gambar 2).

5) Pendampingan masyarakat Desa Wringinputih untuk menjadi desa percontohan ketahanan pangan dengan memanfaatkan sumber daya alam (SDA) lokal melalui diversifikasi oahan makanan dari bahan dasar ketela.

6) Pendampingan masyarakat Desa Wringinputih untuk menjadi desa percontohan ketahanan pangan dengan memanfaatkan sumber daya alam (SDA) lokal melalui diversifikasi oahan makanan dari bahan dasar ketel

\section{SIMPULAN}

Dalam pelaksanaan kegiatan pengabdian masyarakat dalam rangka pengembangan keberlanjutan usaha kecil menengah produk makanana olahan di Desa Wringinputih ini dapat disimpulkan sebagai berikut:

1) Pelaksanaan kegiatan pengabdian masyarkat mendapatkan respon yang positif dari pemerintah desa, Dinas
Perindutrian Perdagangan dan Koperasi Kabupaten Magelang dan anggota UKM kerajinan makanan ketela.

2) Produk dari hasil kegiatasan berupa dokumen perencanaan /masterplan pengembangan usaha UKM akan di gunakan sebagai usulan dana desa pada tahun 2018

3) Kegiatan PKM ini dapat menjadi kegiatan yang berkelanjutan untuk kegiatan PKM pada periode berikutnya dengan program pendampingan untuk realisasi program

4) Kegiatan PKM yang telah dilaksankan dengan skim KKN PPM ini mamapu meningkatkan motivasi anggota, memberikan wawasan dan pengetahuan pengembangan usaha berupa diversifikasi produk, menghasilkan dokumen sebagai syarat pengajuan P-IRT, bentuk kemasan produk (packeging), label produk (labelling), dan strategi pemasaran produk makanan olahan ketela

\section{UCAPAN TERIMA KASIH}

Penulis mengucapkan terima kasih kepada Direktorat Riset dan Pengabdian masyarakat (DRPM), Kementerian Riset, Teknologi dan Pendidikan Tinggi yang telah memberikan dana hibah untuk pelaksanaan kegiatan Pengabdian Masyarakat KKN-PPM 2017 berdasarkan Surat Tugas Nomor: 006/STRek/80/DPPM/KKN PPMKEMENRISTEKDIKTI/III/2017.

\section{DAFTAR PUSTAKA}

Pattinama, M. J., (2009), Pengetasan Kemiskinan Dengan Kearifan Lokal (Studi Kasus di Pulau Buru-Maluku dan Surade-Jawa Barat), Jurnal 
Makara Sosial Humaniora, 13 (1), $1-12$.

Sahudiyono (2009), Memberdayakan Masyarakat Pesisir dengan Pendekatan Program Pemberdayaan Ekonomi Masyarakat Pesisir (PEMP), Jurnal Riset Daerah BAPEDA Bantul, 7(3), 1169-1189.

Situmorang, J., (2007), Kaji Tindak Peningkatan Peran Koperasi dan UKM sebagai Lembaga Keuangan Alternatif, Jurnal Infokop, 2, 24-35.

Suharto, E., (2010), Membangun Masyarakat Memberdayakan Rakyat; Kajian Strategis Pembangunan Kesejahteraan Sosial \& Pekerjaan Sosial, Cet. ke-4, PT Refika Aditama: Bandung.

Rachman, A. N., Muhamad, C., Ramdani, S., Kunci, K., \& Geulis, K. (2016). IbM Pelatihan Pemanfaatan ECommerce Sebagai Media Pemasaran Global Untuk Peningkatan Penjualan Produk Kelom Geulis ( Studi Kasus : UKM kelom geulis Tamansari Tasikmalaya). Jurnal Siliwangi 2 (1), 64-68.

Sutrisno, J. (2011). Kewirausahaan Dan Pengembangan Teknologi UMK. Infokop, 19 (April), 86-103.

Wardhani, I.M., (2010), Evaluasi Program Community Development Mengentaskan Kemiskinan (CDMK) di Kabupaten Bantul Tahun 2006-2009 (Study Kasus Desa Bangunharjo dan Desa Timbulharjo), Skripsi tidak dipublikasikan, Universitas Muhammadiyah Yogyakarta.

Yulianto, T., (2005), Fenomena ProgramProgram Pengetasan Kemiskinan di Kabupaten Klaten (Studi Kasus di Desa Jotangan Kecamatan Bayat),
Tesis tidak dipublikasikan, Universitas Diponegoro, Semarang. 